\title{
"Political elections, abnormal returns and stock price volatility: the case of Greece"
}

$\begin{array}{ll} & \text { Athanasios Koulakiotis } \\ \text { AUTHORS } & \text { Harry Papapanagos } \\ & \text { Nicholas Papasyriopoulos }\end{array}$

Athanasios Koulakiotis, Harry Papapanagos and Nicholas Papasyriopoulos

ARTICLE INFO (2016). Political elections, abnormal returns and stock price volatility: the case of Greece. Investment Management and Financial Innovations, 13(1-1), 161-169. doi:10.21511/imfi.13(1-1).2016.03

DOI http://dx.doi.org/10.21511/imfi.13(1-1).2016.03

RELEASED ON Friday, 08 April 2016

JOURNAL "Investment Management and Financial Innovations"

FOUNDER LLC "Consulting Publishing Company "Business Perspectives"

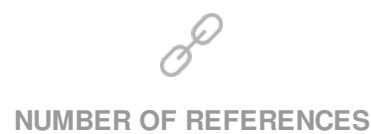

0

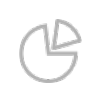

NUMBER OF FIGURES

0

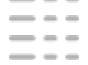

NUMBER OF TABLES

0

(C) The author(s) 2022. This publication is an open access article. 


\title{
Athanasios Koulakiotis (Greece), Harry Papapanagos (Greece), Nicholas Papasyriopoulos (Greece) Political elections, abnormal returns and stock price volatility: the case of Greece
}

\begin{abstract}
The impact of the Greek political elections on the return and volatility of the Athens Stock Exchange (ASE) is investigated using both the standard event study methodology and various univariate GARCH models. The empirical results reveal positive pre- and post-election abnormal returns, but negative on the day of the election. Strong evidence is also found that suggests that the election outcome significantly affects the ASE return; however, the evidence is rather limited for the ASE volatility. The empirical findings raise doubts about the efficiency of the Greek stock market and might have important implications for investors with respect to decisions regarding entering and/or exiting the market or investment strategies around time periods where political elections are going to take place.
\end{abstract}

Keywords: political elections, stock price volatility, Athens Stock Exchange, GARCH models.

JEL Classification: C20, G14, G15.

\section{Introduction}

Greece is known as the birthplace of democracy and has a long history of political elections. In recent years, after the collapse of the military junta in 1974 and the restoration of the parliamentary democracy, the political environment in Greece is stable with two political parties dominating the political life: the conservative party known as New Democracy (ND) and the socialist party known as the Pan-Hellenic Socialist Movement (PASOK). These two political parties have succeeded each other in the cabinet for the last 30 years with the socialist party staying considerably longer in power than the conservative party; though the latter is in power since March of 2004 up to the writing of this study.

Although for most of its history the Athens Stock Exchange (ASE) was regarded as a developing stock market, from the middle of 1980s the ASE started to develop notably. The driving forces behind this development were the Investment Services Directive (EC, 1993) aiming at liberalizing the ASE and harmonizing it with the other European stock markets, the convergence of the Greek economy to the European requirements, the stable political environment and improvements in the technical infrastructure. As a result, capital inflows from both domestic and foreign investors increased and the ASE developed considerably in terms of market capitalization, turnover and number of listed companies. During the examined period (19852008), Greece experienced a rather large number of political elections (i.e., 7 election battles) and therefore, it would be interesting to examine

(C) Athanasios Koulakiotis, Harry Papapanagos, Nicholas Papasyriopoulos, 2016.

Athanasios Koulakiotis, Department of Balkan, Slavic and Oriental Studies, University of Macedonia, Greece.

Harry Papapanagos, Department of Balkan, Slavic and Oriental Studies, University of Macedonia, Greece.

Nicholas Papasyriopoulos, Department of Balkan, Slavic and Oriental Studies, University of Macedonia, Greece. whether these political changes had a significant effect on the ASE return and volatility.

Our paper investigates the stock price index response around the election dates and the effects of change in the ruling political party in Greece on the return and risk in the ASE. In particular, the traditional and very popular event study methodology, described well by Dodd and Warner (1983) and Brown and Warner (1985), is adopted to examine the behavior of the ASE composite index daily return around the election dates during the period from January 1985 to February 2008, while the AR(1)-GARCH, AR(1)EGARCH and AR(1)-GJR-GARCH models are employed, as proposed by Lin and Wang (2005), to examine the impact of the government change on the stock return and volatility of the ASE. Our primary objective is to observe whether the risk undertaken by investors around the election dates is compensated by higher returns.

Besides adding to the rather limited literature, the results of this study can also be of particular importance to investors concerned with decisions regarding the entry to and/or exit from the market as well as changes of investment strategies.

The remainder of the paper is set out as follows. Section 1 briefly reviews the literature on the impact of political elections on the stock market, Section 2 describes the recent development in the ASE, Section 3 outlines the data and the methodology and Section 4 analyzes the empirical results. Final section summarizes and concludes the paper.

\section{Literature review}

One of the first researchers who analyze the relationship between economics and politics was Nordhaus (1975) who showed that elections induced significantly economic cycle in the US. It has long been argued that major political events such as elections can have a significant impact on the stock market. For example, Pantzalis et al. (2000) found 
that stock market prices tend to respond to new information regarding political decisions that may affect a nation's fiscal and monetary policy. Other studies investigated the effects of economic events on presidential voting and the impact of different political structures to various economic variables (see, for example, Atesoglou and Congleton, 1982; and Burdekin, 1988). Bratsiotis (2000), for example, examined the inflationary consequences of elected political parties in Greece before and after its commitment to the Single European Act (SEA) ${ }^{1}$ in 1986 and found that inflation plays a significant role in the political partisan cycle in Greece after the introduction of SEA.

Another set of studies examined the stock market efficiency around political election dates. Gemmill (1992), for example, found an extremely close relationship between polls and the FTSE 100 index. However, there was evidence of gross inefficiency in options prices in the UK during the last week of the elections period, implying a low probability of a conservative party win, while the opinion polls showed the opposite. A number of studies have also studied the impact of political elections on stock market returns (see, for example, Huang, 1985; and Foerster and Schmitz, 1997). In general, the results of these studies supported the so-called presidential election cycle hypothesis according to which the US stock market offers higher return in years 3 and 4 than in years 1 and 2 of a presidential term ${ }^{2}$. In addition, Pantzalis et al. (2000) investigated the stock market performance around political elections using data from 33 developed and developing countries around the world. They found a positive stock market reaction in the two week-period preceding election dates. This positive abnormal return was stronger for elections with higher degree of uncertainty ${ }^{3}$. Kim and Mei (2001) found that political developments in Hong Kong had a significant impact on volatility and return while Chan and Wei (1996) and Bittlingmayer (1998) found evidence that positive political news positively affect currency and equity markets.

More recently, Siokis and Kapopoulos (2007) examined whether movements in the ASE stock prices could be partially explained by the dynamics of the political environment. Using an EGARCH-M

\footnotetext{
${ }^{1}$ The Single European Act can be considered as the first formal attempt towards the economic and political convergence and integration of EU country members.

${ }^{2}$ This is mainly because the first and second year of the presidential term are considered to be more appropriate to introduce unpopular changes such as tax increases. As business profits suffer the negative effects of these policies, earnings shortfalls lead to negative or low stock market returns.

${ }^{3}$ Similar findings were reported in the literature for the case of the UK stock market by Peel and Pope (1983).
}

model and daily data for the ASE composite index from January 1987 to June 2004, they found that political changes have a significant impact on the conditional variance in the ASE and they also presented evidence that the behavior of the return is asymmetrically affected by past innovations. They also reported that volatility increases more in the pre-election period and when the right-wing party is in power.

Bialkowski et al. (2008) investigated a sample of 27 OECD countries to test whether national elections bring about higher stock market volatility. Greece's election battle of March 2004 was also among the presidential and parliamentary elections that were investigated in their study. The authors provided evidence that stock market volatility was substantially higher (about double) than normal around election dates, a finding that was interpreted as an element of surprise on the part of investors. According to Bialkowski et al. (2008), "several factors, such as a narrow margin of victory, lack of compulsory voting laws, change in the political orientation of the government, or the failure to form a government with parliamentary majority significantly contributed to the magnitude of the election shock". Finally, it was found that stock markets with short trading history had stronger market reaction around election dates.

\section{The Athens Stock Exchange}

Until the late 1980s the ASE has attracted little attention from both local and international investors mainly because of its domestic character, the inefficient and incomplete regulation as well as the lack of technical infrastructure. However, a series of changes and innovations, started to take place in the late 1980 s, led to considerable growth in terms of number of listed companies, market capitalization and shares turnover. In particular, in 1985 the capital and profit requirements as well as the duties and obligations for companies listed in the ASE were introduced, while in 1986 all restrictions regarding the liquidation of investments and repatriation of profits from non-Greek residents were abolished. In 1991, the Capital Market Commission was established as a supervisory authority and the legal framework regarding the regulation and operation of investment companies and mutual funds were introduced. In 1992, electronic trading was introduced and the legal framework regarding inside trading was established. Alongside these changes, the commitment of Greece to meet the convergence economic criteria in order to join the European Monetary Union created a positive sentiment to investors and in the late of 1990s the ASE started to rally. The ASE composite index rose from 868 in 1994 to 5,535 in 1999 while 
the annual return offered to investors was $85 \%$ in 1998 and $102 \%$ in 1999. The influx of international funds during that period was so remarkable that contributed to the rise of the ASE composite index in record levels reaching 6,355 on October 17, 1999. The shares turnover also increased significantly from $€ 3,703$ millions in 1994 to $€ 173,000$ millions in 1999 . Equity issues also rose from $€ 772$ millions in 1994 to $€ 10,000$ millions in 1999 and new listings went up from 12 in 1997 to 37 in 1999 and 53 in 2000.

The flow of international funds ${ }^{4}$ in the Greek capital market was phenomenal giving a sense of euphoria to local investors. However, the rally came to an end when the international institutional investors found the market overvalued and decided that it was time to start realizing profits. The events of September $11^{\text {th }} 2001$ created a negative sentiment in the global markets and that had a significant effect on the ASE. The ASE composite index plummeted from 3,388 in 2000 to 1,748 in 2002 with the annual return offered to be $-38 \%$ in $2000,-23 \%$ in 2001 and $-32 \%$ in 2002. Shares turnover decreased from $€ 101,000$ millions in 2000 to $€ 25,000$ millions in 2002 . Equity issues also decreased from $€ 9,870$ millions in 2000 to $€ 1,934$ millions in 2002. By the end of March of 2003, the majority of Greek stocks had lost more than half of their values and in some cases, more than $90 \%$ of their values. However, by the end of March of 2003 and until the mid of 2007, the ASE composite index experienced a gradual up trend following that of major developed capital markets such as the UK and the US markets. The subprime mortgage loans crisis in the US in the mid of 2007 was the first sign that global capital markets could not sustain their positive momentum and the ASE could not be the exception. In an effort to protect investors' interest, in November of 2007 the Capital Market Commission adopted the Markets in Financial Instruments Directive (MiFID) which provides a harmonised regulatory regime for investment services across the 30 member states of the European Economic Area (the 27 country members of the European Union plus Iceland, Norway and Liechtenstein) and aims to increase competition and consumer protection in investment services. More recently, the ASE created another market which is called "alternative market" that is adressed for small companies in terms of market capitalization and profits. Finally, exchange traded funds (ETF) were also recently introduced in the ASE.

\section{Data and methodology}

3.1. Data description. Daily returns of the ASE composite index were collected from the

\footnotetext{
4 According to daily financial press, the flow of international funds exceeded 1 billion Euros during the examined period.
}

Dissemination Information Department of the ASE from January 1985 to February 2008. During this period, 8 political elections took place in Greece; $18 / 6 / 89,5 / 11 / 89,8 / 4 / 90,10 / 10 / 93,22 / 9 / 96,9 / 4 / 00$, $7 / 3 / 04$ and $16 / 9 / 07$. However, the two election dates $5 / 11 / 89$ and $8 / 4 / 90$ were excluded from the sample as they were runner up elections of that of $18 / 06 / 89$ where the winning political party could not form a majority government. In addition, since elections in Greece take place on Sundays, we define the Election Day (day 0) as the first trading day after the election. It should be pointed out that Greece has mandatory voting laws regarding parliamentary elections and voters' participation exceeds $70 \%$.

Table 1 reports descriptive statistics of the daily returns of the ASE composite index. The daily mean return was $0.08 \%$ and the daily standard deviation was $1.74 \%$. An examination of Table 1 also reveals that the hypothesis that daily returns follow a normal distribution can be rejected due to the large value of kurtosis (14.15); also confirmed by the Kolmogorov-Smirnov test statistic. In addition, the Ljung-Box (LB) test statistic rejects the hypothesis that all autocorrelations up to 10 lags are zero for both the returns and squared returns which justifies the use of ARCH-type models for the variance.

Table 1. Descriptive statistics of the ASE composite index daily returns

\begin{tabular}{|l|c|}
\hline Mean $(\%)(\mu)$ & 0.08 \\
\hline Standard deviation $(\%)(\sigma)$ & 1.74 \\
\hline Skewness $(S)$ & $0.31^{*}$ \\
\hline Kurtosis $(K)$ & $14.15^{*}$ \\
\hline Kolmogorov-Smirnov test statistic & $0.095^{*}$ \\
\hline $\mathrm{LB}(10)$ & $282.74^{*}$ \\
\hline $\mathrm{LB}^{2}(10)$ & $1790.84^{*}$ \\
\hline
\end{tabular}

Note: This table contains descriptive statistics for the ASE daily returns over the period from January 1985 to February 2008. $*$ denotes statistical significance at the $5 \%$ significance level. $\mu$, $\sigma, S$ and $K$ are the mean, standard deviation, skewness and kurtosis, respectively. The Kolmogorov-Smirnov test statistic examines the hypothesis that the ASE returns are normally distributed (the critical value at the $5 \%$ level is $1.36 / \sqrt{n}$, where $n$ is the sample size). $\mathrm{LB}(10)$ and $\operatorname{LB}^{2}(10)$ are the 10 lags Ljung-Box statistics calculated for the returns and the squared returns, respectively. The LB statistic is distributed as $\chi^{2}$ with $n$ degrees of freedom; where $n$ is the number of lags being tested.

However, even though the LB statistic provides evidence for second-moment time dependencies, it cannot be used to test the asymmetric return volatility of bad and good news because it is a statistical test which accounts for only the amount of serial correlation in the return series. Therefore, to investigate whether the shocks on the ASE returns have an asymmetric effect on volatility, the diagnostics proposed by Engle and $\mathrm{Ng}$ (1993) are used. These include (i) the sign bias test, (ii) negative size bias test, (iii) positive size bias test, 
and (iv) joint test. The first test examines the impact of positive and negative innovations on volatility not predicted by the Engle and $\mathrm{Ng}$ (1993) model. In particular, the squared residuals of the initial AR(1) model are regressed against a constant and a dummy $\mathrm{S}_{t}^{-}$that takes the value of one when $\varepsilon_{t-1}$ is negative and zero otherwise. The impact of large and small negative innovations on volatility is captured by the negative size bias test. It is based on the regression of the standardized residuals against a constant and $\mathrm{S}_{t}^{-} \varepsilon_{t-1}$. The calculated t-statistic for $\mathrm{S}_{t}^{-} \varepsilon_{t-1}$ is used to test for the biases. The positive sign bias test examines possible biases of the estimated results associated with large and small positive innovations. The standardized filtered residuals are regressed against a constant and $\left(1-\mathrm{S}_{t}^{-}\right) \varepsilon_{t-1}$. Again, the t-statistic for $\left(1-\mathrm{S}_{t}^{-}\right) \varepsilon_{t-1}$ is used to test for the possible biases. Finally, the joint test uses the F-test based on a regression that included all three variables, i.e. $\mathrm{S}_{t}^{-}, \mathrm{S}_{t}^{-} \varepsilon_{t-1}$ and $\left(1-\mathrm{S}_{t}^{-}\right) \varepsilon_{t-1}$. The calculated t-statistics as well as the F-statistic of these regressions are reported in Table 2.

Table 2. Volatility specification tests for filtered returns

\begin{tabular}{|l|c|}
\hline Sign bias $(t$-test) & -0.057 \\
\hline Negative size bias $(t$-test) & $-0.61^{*}$ \\
\hline Positive size bias $(t$-test) & $0.61^{*}$ \\
\hline Joint test $F(3,5762)$ & $160.53^{*}$ \\
\hline ARCH $(4)$ & $252.11^{*}$ \\
\hline ADF $(1)$ & $-49.88^{*}$ \\
\hline $\operatorname{PP}(4)$ & $-61.47^{*}$ \\
\hline
\end{tabular}

Note: This table reports the tests proposed by Engle and $\mathrm{Ng}$ (1993). These tests investigate whether the return shocks on ASE have an asymmetric effect on volatility and are specified as follows:

Sign bias: $z_{t}^{2}=\alpha+b S_{t}^{-}+e_{t}$

Negative sign bias: $z_{t}^{2}=\alpha+b S_{t}^{-} \varepsilon_{t-1}+e_{t}$

Positive sign bias: $z_{t}^{2}=\alpha+b\left(1-S_{t}^{-}\right) \varepsilon_{t-1}+e_{t}$

Joint test: $z_{t}^{2}=\alpha+b_{1} S_{t}^{-}+b_{2} S_{t}^{-} \varepsilon_{t-1}+b_{3}\left(1-S_{t}^{-}\right) \varepsilon_{t-1}+e_{t}$,

where $\mathrm{S}_{t}^{-}$is a dummy variable that takes the value of one if $\varepsilon_{t-1}$ is negative and zero otherwise. All t-statistics refer to the coefficient $b$ in the first three regressions, while the joint test $\mathrm{F}(3,5217)$ refers to the fourth regression. The normalized residuals $z^{t}=\varepsilon_{i} / \sigma_{i}$ are based on an AR (1) model applied to the daily returns. ARCH denotes the Lagrange multiplier test of Engle (1982) and the critical value is 7.82 at the 5\% significance level. ADF denotes the Augmented Dickey Fuller test statistic, PP denoted the Phillips-Perron test statistic and the lag interval is determined by minimizing the Akaike (AIC) and Schwarz Bayesian (SBC) criteria values. The functions of the $\mathrm{AIC}$ and $\mathrm{SBC}$ criteria are:

$\operatorname{AIC}(\mathrm{k})=\mathrm{T} \times \ln \sigma_{t}^{2}+2 \mathrm{k}$ and $\mathrm{SBC}(\mathrm{k})=\mathrm{T} \times \ln \sigma_{t}^{2}+\mathrm{k} * \ln \mathrm{T}$,

where $\mathrm{k}$ denotes the lagged period, $\mathrm{T}$ denotes the number of sample, and $\sigma_{t}^{2}$ denotes the lagged $\mathrm{k}$ periods of $\sum_{i=1}^{T} \varepsilon_{t}^{2}$. The critical value for the ADF test is equal to -2.863 . * Denotes statistical significance at the 5\% significance level. Both the $\mathrm{ADF}$ and PP tests reject the null hypothesis that the ASE returns have a unit root at any conventional significance level.
The results indicated statistically significant negative size bias, statistically significant positive size bias and a significant joint F-test, suggesting the presence of asymmetries in the conditional variance. In addition, volatility was found to exhibit conditional heteroskedasticity. Both the Augmented Dickey Fuller (ADF) and Phillips-Perron (PP) tests reject the null hypothesis that there is a unit root in the ASE returns ${ }^{5}$ at any conventional significance level (see Table 2). The unconditional kurtosis of the ASE daily returns reported in Table 3 was 13.34. In addition, the residuals had zero mean and unity variance. The estimated LB statistics for 5 and 10 lags rejects the hypothesis of nonlinear dependence in the normalized residuals and squared normalized residuals. This means that an ARCH type model could be used to describe the behavior of the normalized residuals and the behavior of the squared normalized residuals since the autocorrelations of 5 and 10 lags for the normalized and the squared normalized residuals were statistically significant. Overall, the evidence supports the inclusion of conditional heteroskedastic and asymmetric components in the volatility equation specification in order to model adequately the ASE volatility.

Table 3. Diagnostic tests for the residuals

\begin{tabular}{|l|c|}
\hline Kurtosis $(K)$ & $13.34^{*}$ \\
\hline$E\left(z_{t}\right)$ & $-20^{-8}$ \\
\hline$E\left(z_{t}^{2}\right)$ & 2.91 \\
\hline$L B(5)$ & $13.36^{*}$ \\
\hline$L B(10)$ & $35.13^{*}$ \\
\hline$L B^{2}(5)$ & $1475.16^{*}$ \\
\hline $\mathrm{LB}^{2}(10)$ & $1843.22^{*}$ \\
\hline
\end{tabular}

Note: * Denotes statistical significance at the $5 \%$ significance level. $z_{t}$ is the model normalized residual. $\mathrm{LB}($.$) and \mathrm{LB}^{2}($.$) are$ the Ljung-Box test statistics for the $z_{t}$ and $z_{t}^{2}$, using 5 and 10 lags, respectively. The residuals came from an AR(1) model.

3.2. Methodology. 3.2.1. The mean-adjusted return model. The classical event study methodology described by Dodd and Warner (1983) and Brown and Warner (1985) was employed to estimate the ASE index return reaction around the day of an election. We define as day zero $(t=0)$ the first trading day following the election date. Using the mean-adjusted return model, abnormal returns ${ }^{6}$ $\left(A R_{t}\right)$ of the ASE composite index around the first

\footnotetext{
${ }^{5}$ Siokis and Kapopoulos (2007) found that a unit root exists in the level of the ASE index. However, they used stock prices instead of log returns. This means that if there is not a unit root in the return series of the ASE we do not need to take into account second logarithmic differentiation of the series.

${ }^{6}$ The ASE logarithmic returns were calculated according to the formula $R_{t}=\ln \left(P_{t} / P_{t-1}\right)$, where $P_{t}$ is the index price on day $t$ and $P_{t-1}$ is the index price on day $t-1$.
} 
post-election day are calculated as the difference between the ex-post return $R_{t}$ and the normal return $\bar{R}_{t}$ :

$$
A R_{t}=R_{t}-\bar{R}_{t},
$$

where the normal return for the ASE composite index $\left(\bar{R}_{t}\right)$ is the mean historical return over a 250 days period prior to the event period, that is, from day -260 to day -11 . The event period is a $21-$ day window around the first post-election day $(t=0)$; that is, from $t=-11$ to $t=+11$. The statistical significance of the mean abnormal return was tested using the t-statistic, while the statistical significance of the median abnormal return was tested using the Wilcoxon signed rank test ${ }^{7}$.

3.2.2. ARCH-type modeling approach. A number of studies have used the so-called GARCH, E-GARCH models of Nelson (1991) and the GJR-GARCH model of Glosten, Jagannathan, and Runkle (1993) (see, for example, Bollerslev, 1986; Friedman and Sanddorf-Kohle, 2002; and Siokis and Kapopoulos, 2007). The first model (GARCH) is symmetric which means that positive and negative innovations on the conditional volatility have the same impact with regards to the arrival of news; however, this does not hold for the case of the two asymmetric models. Having assessed the ability of all three models to describe the daily ASE returns volatility, the effects of transition of the ruling party on the stock market behavior is also examined. Dummies are also included in the three afore-mentioned models to detect the effect of transition of the ruling party on stock price returns and volatility as follows:

$$
R_{t}=\alpha_{0}+\alpha_{1} D_{1}+\alpha_{2} D_{2}+\alpha_{3} R_{t-1}+\varepsilon_{t},
$$

where $\varepsilon_{t} \mid \Omega_{t-1} \sim T\left(0, h_{t}\right)$. $D_{1}$ denotes the dummy variable that takes the value of 1 for the transition of ruling party and 0 otherwise. The second dummy variable $D_{2}$ controls for the stock market crash of October 1987 where there was a large increase in volatility ${ }^{8}$. Therefore, the sample period is broken into the pre-1987 and post-1987 period. In particular, dummy $D_{2}$ equals 1 for the post-1987 period and 0 for the pre-1987 period. The symmetric response to shocks is taken from Bollerslev's (1986) GARCH model:

\footnotetext{
${ }^{7}$ The Wilcoxon signed rank test, also known as the Wilcoxon matched pairs test, is a non-parametric test used to test the median difference in paired data. This test is the non-parametric equivalent of the paired $t$ test. The Wilcoxon signed rank procedure assumes that the sample is randomly taken from a population which has a symmetric probability distribution. The symmetric assumption does not assume normality; it simply assumes that there is roughly the same number of values above and below the median.

${ }^{8}$ We control for the impact of October 1987 crash because it is known that it increases volatility (Aggarwal, Inclan and Leal, 1999; and Nich, 2002).
}

$h_{t}=\tau_{0}+\tau_{1} D_{1}+\tau_{2} D_{2}+\beta_{1} h_{t-1}+\beta_{2} \varepsilon_{t-1}^{2}$,

the parameter restrictions, $\tau_{0}>0, \beta_{1} \geq 0, \beta_{2} \geq 0$ and $\beta_{1}+\beta_{2}<1$, ensure that the stochastic process $\left(\varepsilon_{t}\right)$ is well-defined (i.e., $\left.h_{t}>0\right)$ and the covariance is stationary with, $E\left(\varepsilon_{t}\right)=0, \operatorname{Var}(\varepsilon)=h_{t}$ and $\operatorname{cov}\left(\varepsilon_{t}, \varepsilon_{s}\right)=0$.

To allow for asymmetric volatility effects the EGARCH and the GJR-GARCH models are also considered. The E-GARCH asymmetric volatility model is given by:

$$
\begin{aligned}
& \ln h_{t}=\tau_{0}+\tau_{1} D_{1}+\tau_{2} D_{2}+\beta_{1} \ln h_{t-1}+ \\
& +\beta_{2}\left[\left|u_{t-1}\right|-E\left|u_{t-1}\right|+\theta u_{t-1}\right]
\end{aligned}
$$

where $u_{t}=\varepsilon_{t} / \sqrt{h_{t}}$. The news $\varepsilon_{t-j}$ impact on conditional volatility $\ln \left(h_{t}\right)$. The model captures an asymmetric response because:

$\partial \ln h_{t} / \partial \varepsilon_{t-1}=\beta_{2}(\theta+1)$, when $\varepsilon_{t-1}>0$, and

$\partial \ln h_{t} / \partial \varepsilon_{t-1}=\beta_{2}(\theta-1)$, when $\varepsilon_{t-1}<0$,

volatility is minimized in the absence of news, $\varepsilon_{t-1}=0$.

The GJR-GARCH asymmetric volatility model is described by:

$h_{t}=\tau_{0}+\tau_{1} D_{1}+\tau_{2} D_{2}+\beta_{1} h_{t-1}+\beta_{2} \varepsilon_{t-1}^{2}+\beta_{3} \bar{S}_{t-1} \varepsilon_{t-1}^{2}$,

where $\bar{S}_{t-1}=\left\{\begin{array}{lll}1 & \text { if } & \varepsilon_{e-1}<0 \\ 0 & \text { if } & \varepsilon_{t-1} \geq 0\end{array}\right.$

and the process is well-defined when $p \geq 0, q \geq 0, \tau_{0}>0, i=1,2,3, \ldots, p$,

$\beta_{1}>0, j=1,2,3, \ldots, q$.

The maximum likelihood (ML) estimation method, as it is very common, is used to estimate the parameters of the mean and the time-varying conditional variance-covariance equations ${ }^{9}$.

\section{The empirical results}

4.1. The stock market reaction around six election dates. Table 4 reports the abnormal returns (ARs) for the 6 election dates for the event period which started 10 days before the election date $(t=-10)$ and ended 10 days after the election date $(t=+10)$. It can be noticed that the average AR is positive on day -1 and equal to $1.04 \%$ which is statistically significant at the $10 \%$ significance level, whereas the median AR is $0.49 \%$ and statistically significant at the $5 \%$ significance level. On the first trading day after the election date (day 0), the ASE reacts negatively having a mean (median) abnormal

\footnotetext{
${ }^{9}$ The BHHH algorithm proposed by Berndt et al. (1974) was used to obtain the maximum likelihood estimates of the parameters.
} 
return equal to $-1.65 \%(-0.28 \%)$. The sign of the abnormal return becomes positive on days 1 and 2, without, however, being statistically significant (a mean equal to $0.46 \%$ and $0.29 \%$ on days +1 and +2 , respectively). This result can be attributed to the fact that the election result is officially announced at the end of the following working day (Monday in our case) and, therefore, the stock market incorporates that information one day later. Moreover, the negative market reaction on day 0 can be also attributed to the outcome of the elections which leads to the formation of a government with marginal MP majority ${ }^{10}$, signaling to the market that the winning party is prone to populist pressures by labor unions and other social forces. On the other hand, the positive reaction of the ASE before the Election Day can be attributed to the formation of investors' expectations that the new government will fulfill its pre-electoral promises and a new era of economic prosperity will begin. These results are in line with those of Pantzalis et al. (2000), who employed a sample of both developed and developing countries and found positive market reaction prior to the election dates and negative market reaction on the election date, even though they used weekly data instead of daily ones. As far as the possible occurrence of the day-of-the-week effect $^{11}$ in the ASE, it should be noticed that there is no consensus. Alexakis and Xanthakis (1995) found significant negative returns on Tuesdays and positive returns on the other days of the week for the period from January 1985 to February 1994. Coutts et al. (2000) found significant positive returns on Fridays and insignificant returns on the other days of the week for the period from October 1986 to August 1996. Mills et al. (2000) found significant positive returns on Fridays and negative returns on Wednesdays for the period from October 1986 to April 1997. Al-Khazali et al. (2008), using stochastic dominance analysis, found evidence of the highest returns occurring on Fridays and the lowest on Tuesdays for the period from January 1985 to December 2004. Finally, Tsangarakis (2008) revealed that the day-of-the-week effect is not a dominant phenomenon of the Greek stock market. Therefore, we can argue that our finding of negative stock returns on the Election Day which is always on Monday cannot be attributed to the dayof-the-week effect.

\footnotetext{
${ }^{10}$ Three out of six elections resulted in the formation of a government with marginal majority.

11 According to the day-of-the-week effect or Monday effect or weekend effect, on average, stock returns are higher on Fridays, that is, the last trading day of the week, and negative on Mondays which is the first trading day of the week.
}

Table 4. ASE return behavior over a period of 21 days around 6 election dates

\begin{tabular}{|c|c|c|c|c|}
\hline Day & Mean \% & $\begin{array}{c}p \text {-value } \\
\text { (t-test) }\end{array}$ & Median \% & $\begin{array}{c}p \text {-value (Wilcoxon } \\
\text { signed rank test) }\end{array}$ \\
\hline-10 & 0.01 & 0.993 & -0.31 & 0.402 \\
\hline-9 & -0.54 & 0.239 & -0.36 & 0.529 \\
\hline-8 & 0.00 & 0.996 & -0.24 & 1.000 \\
\hline-7 & 0.40 & 0.157 & 0.56 & 0.142 \\
\hline-6 & 0.44 & 0.283 & 0.38 & 0.208 \\
\hline-5 & -0.18 & 0.744 & -0.10 & 0.675 \\
\hline-4 & -0.02 & 0.951 & -0.05 & 1.000 \\
\hline-3 & $-0.53^{*}$ & 0.051 & $-0.36^{* *}$ & 0.036 \\
\hline-2 & 0.28 & 0.285 & 0.12 & 0.402 \\
\hline-1 & $1.04^{*}$ & 0.060 & $0.49^{* *}$ & 0.036 \\
\hline 0 & -1.65 & 0.299 & -0.28 & 0.402 \\
\hline 1 & 0.46 & 0.389 & 0.50 & 0.529 \\
\hline 2 & 0.29 & 0.677 & 0.11 & 0.834 \\
\hline 3 & -0.83 & 0.352 & -0.73 & 0.402 \\
\hline 4 & -1.22 & 0.236 & -0.66 & 0.208 \\
\hline 5 & -2.49 & 0.160 & $-1.39^{*}$ & 0.093 \\
\hline 6 & -0.10 & 0.890 & 0.34 & 1.000 \\
\hline 7 & 1.91 & 0.162 & 0.94 & 0.142 \\
\hline 8 & 0.10 & 0.840 & -0.29 & 1.000 \\
\hline 9 & 0.80 & 0.394 & 0.25 & 0.529 \\
\hline 10 & -0.66 & 0.434 & -0.39 & 0.675 \\
\hline
\end{tabular}

Note: The mean abnormal returns (ARs) of the ASE index is the difference between the ex-post return $R_{t}$ and the normal return $\bar{R}_{t}$ which is the mean historical return over a 250 -day period prior to the event period, that is, from day -260 to day -11 . The Wilcoxon signed rank test is a non-parametric test used to test the median difference in paired data. ${ }^{* *}$ and $*$ indicate statistical significance at the $5 \%$ and $10 \%$ significance levels, respectively.

\subsection{The stock market returns and volatility} around election dates. Tables 5 to 7 report the coefficients of transition of ruling party dummies, $\alpha_{1}\left(-32^{-2}\right.$ for the AR(1)-GARCH model, $-22^{-2}$ for the AR(1)-E-GARCH model and $-33^{-2}$ for the AR(1)GJR-GARCH model) and $\tau_{1}\left(50^{-4}\right.$ for the AR(1)GARCH model, 1.19 for the AR(1)-E-GARCH model and $51^{-4}$ for the AR(1)-GJR-GARCH model). These estimates are statistically significant at the $5 \%$ significant level for all the models when we consider the stock price returns, but only for the AR(1)-E-GARCH model when we consider volatility. Therefore, the transition of ruling party in Greece has an important impact on the ASE return, according to the three GARCH models, and an important impact on volatility, according to the AR(1)-E-GARCH model. Therefore, the above finding does not hold for the AR(1)-GARCH, and AR(1)-GJR-GARCH models when we consider volatility, regardless if the model captures symmetric or asymmetric news. This finding is in agreement with Lin and Wang (2005) who also found no significant relationship between the dummy of transition of ruling party and the stock 
returns and volatility of the Nikkei 225 stock index. This was interpreted as that the political elections and environment when a prime minister succeeds does not influence the Japanese stock market behavior.

The values of the dummy variable $\alpha_{2}$ that controls for the 1987 stock market crash $\left(-66^{-4}\right.$ for the AR(1)GARCH model, $51^{-4}$ for the AR(1)-E-GARCH model and $-61^{-4}$ for the AR(1)-GJR-GARCH model) and $\tau_{2}\left(55^{-6}\right.$ for the AR(1)-GARCH model, $67^{-2}$ for the AR(1)-E-GARCH model and $55^{-6}$ for the AR(1)GJR-GARCH model) indicates that the ASE return is negative in most of the cases and statistically significant, while the ASE volatility is significantly positive at the 5\% significance level. Unsurprisingly, the ASE index return volatility, $\tau_{2}$, is found to be significant at the $1 \%$ level and positively related to the 1987 stock market crash (similar findings were reported in the literature by Schwert, 1990; Engle and Mustafa, 1992; and Lin and Wang, 2005). The three models also capture the negative sign of the dummy variable that controls for the 1987 stock market crash for the ASE returns; with the results being statistically significant. These results are in agreement with the findings of Lin and Wang (2005) who found a statistically significant impact of the 1987 crash on stock price returns. This might be attributed to the big impact of the 1987 stock market crash.

The values of the log-likelihood function (22045.59, 22047.30, and 22045.86 for the AR(1)-GARCH, AR(1)-E-GARCH and AR(1)-GJR-GARCH models, respectively) do not indicate great difference in the amount of volatility and noise examined by the three models. Indeed, the amounts of past volatility are equal to $0.75,0.94$ and 0.76 for the $\mathrm{AR}(1)$ GARCH, AR(1)-E-GARCH and AR(1)-GJRGARCH models, respectively. In addition, the amount of past noise for the AR(1)-GARCH and for the AR(1)-GJR-GARCH model is 0.24 and 0.23 , respectively. There is no analogous coefficient for the case of E-GARCH model as this model captures the impact of bad and good news arising from shocks with different signs. In particular, if $\varepsilon_{\mathrm{t}-1}<0$ (bad news) then the impact of bad news on volatility ${ }^{12}$ is equal to $-0.41[0.41 \times$ $(-0.0018-1)]$ and if $\varepsilon_{t-1} \geq 0$ (good news) then the impact of good news on volatility ${ }^{13}$ is equal to $0.40[0.41 \times(-0.0018+1)]$. The analogous coefficient of the GJR-GARCH model for the case of bad news is equal to 0.0012. This

\footnotetext{
${ }^{12}$ The formula used is $\alpha(\theta-1)$.

${ }^{13}$ The formula used is $\beta_{2}(\theta+1)$.
}

coefficient indicates that the impact of bad news on volatility is smaller in magnitude in the GJRGARCH model compared to the E-GARCH model. The difference is due to the fact that the value of $\beta_{2}$ is large and statistically significant at the $1 \%$ significance level in the E-GARCH model. Thus, the impact of noise on volatility has a bigger shortterm effect with the E-GARCH model compared to the statistically insignificant impact of bad news on volatility in the GJR-GARCH model.

Table 5. Empirical results for the AR(1)-GARCH $(1,1)$ model

\begin{tabular}{|c|c|c|c|}
\hline \multicolumn{4}{|c|}{$\begin{array}{l}R_{t}=\alpha_{0}+\alpha_{1} D_{1}+\alpha_{2} D_{2}+\alpha_{3} R_{t-1}+\varepsilon_{t} \\
h_{t}=\tau_{0}+\tau_{1} D_{1}+\tau_{2} D_{2}+\beta_{1} h_{t-1}+\beta_{2} \varepsilon_{t-1}^{2} \\
D_{1} \text { denotes the dummy of the change of ruling party and } D_{2} \text { denotes the } \\
\text { dummy of } 1987 \text { crash }\end{array}$} \\
\hline Variable & Return & Variable & Volatility \\
\hline$\alpha_{0}$ & $1^{-3}(5.08)^{\star \star \star}$ & $\tau_{0}$ & $29-6(7.25)^{\star \star \star}$ \\
\hline$\alpha_{1}$ & $-32-2(-3.27)^{\star \star \star}$ & $\tau_{1}$ & $50^{-4}(1.42)$ \\
\hline$\alpha_{2}$ & $-66^{-4}(-2.44)^{\star \star \star}$ & $\tau_{2}$ & $55^{-6}(8.41)^{\star \star \star}$ \\
\hline \multirow[t]{5}{*}{$\alpha_{3}$} & $0.20(42.85)^{\star \star *}$ & & \\
\hline & & Coefficient & Estimation \\
\hline & & $\beta_{1}$ & $0.75(106.88)^{\star \star \star}$ \\
\hline & & $\beta_{2}$ & $0.24(25.72)^{\star * \star}$ \\
\hline & & Log-likelihood & 22045.59 \\
\hline
\end{tabular}

Notes: Numbers in parentheses are t-statistics. $* * *, * *$ and $*$ indicate statistical significance at the $1 \%, 5 \%$ and $10 \%$ significance levels, respectively. This table shows the impact of the change of ruling party, the 1987 stock market crash and the previous day's return on next day's returns. The table also shows the impact of the above two mentioned dummy variables plus the previous day's volatility and noise on the next day's volatility. The two equations which comprise an AR(1)-GARCH model have two dummy variables which explain the impact of the change of ruling party and the 1987 stock market crash on volatility. $\alpha_{0}, \alpha_{1}$, $\alpha_{2}$ and $\alpha_{3}$, denote the coefficients for the constant, the dummy for the change of ruling party, the dummy for the 1987 stock market crash and the previous day's returns, respectively. $\tau_{0}, \tau_{1}, \tau_{2}, \beta_{1}, \beta_{2}$ are the coefficients for the constant, the dummy for the change of ruling party, the dummy for the 1987 stock market crash, the previous day's volatility and the previous day's noise, respectively.

Table 6. Empirical results for the AR (1)-E-GARCH $(1,1)$ model

\begin{tabular}{|c|c|c|c|}
\hline $\begin{array}{l}R_{t}=\alpha_{0}+ \\
\ln h_{t}=\tau\end{array}$ & $\begin{array}{l}D_{1}+\alpha_{2} D_{2}+\alpha_{3} R \\
\tau_{1} D_{1}+\tau_{2} D_{2}+\end{array}$ & $+\beta_{2}\left[\mid u_{t-}\right.$ & $\left.\left|u_{t-1}\right|+\theta u_{t-1}\right]$ \\
\hline $\begin{array}{l}D_{1} \text { denote } \\
\text { dummy of }\end{array}$ & $\begin{array}{l}\text { dummy of the } \\
\text { crash }\end{array}$ & of ruling $p$ & Id $D_{2}$ denotes the \\
\hline Variable & Return & Variable & Volatility \\
\hline$\alpha_{0}$ & $96-4(5.78)^{\star * \star}$ & to & $-0.47(-15.67)^{\star \star *}$ \\
\hline$\alpha_{1}$ & $-22^{-2}\left(-2.17^{* *}\right.$ & $\tau_{1}$ & $1.19(2.49)^{\star *}$ \\
\hline$\alpha_{2}$ & $51^{-4}(-2.40)^{\star \star}$ & $\tau_{2}$ & $67^{-2}(6.61)^{\star \star \star}$ \\
\hline$\alpha_{3}$ & $0.25(45.20)^{\star * *}$ & & \\
\hline & & Coefficient & Estimation \\
\hline & & $\beta_{1}$ & $0.94(328.52)^{\star \star *}$ \\
\hline
\end{tabular}


Table 6 (cont.). Empirical results for the AR (1)-E-GARCH $(1,1)$ model

\begin{tabular}{|c|c|c|c|}
\hline Variable & Return & Variable & Volatility \\
\hline & & $\beta_{2}$ & $0.41(35.15)^{\star * *}$ \\
\hline & & $\theta$ & $-18^{-3}(-0.11)$ \\
\hline & & Log-likelihood & 22047.30 \\
\hline
\end{tabular}

Notes: Numbers in parentheses are $t$-statistics. $* * *, * *$ and $*$ indicate statistical significance at the $1 \%, 5 \%$ and $10 \%$ significance levels, respectively. This table shows the impact of the change of ruling party, the 1987 stock market crash and the previous day's returns on next day's returns. The table also shows the impact of the above two mentioned dummy variables plus the previous day's volatility and positive or negative noise on the next day's volatility. The two equations comprise an EGARCH model which has two dummy variables which explain the impact of the change of ruling party and the 1987 stock market crash on volatility. $\alpha_{0}, \alpha_{1}, \alpha_{2}$ and $\alpha_{3}$ are the coefficients for the constant, dummy for the change of ruling party, dummy for the 1987 stock market crash and the previous day's returns of stock, respectively. $\tau_{0}, \tau_{1}, \tau_{2}, \beta_{1}, \beta_{2}$ and $\theta$ are the coefficients for the constant, the dummy for the change of ruling party, the dummy for the 1987 stock market crash, the coefficient of the previous day's logarithmic volatility, the coefficient of the impact of large innovations on conditional volatility suppose that $\theta=0$, and the coefficient of positive and negative innovations, respectively.

Table 7. Empirical results for the AR (1)-GJR GARCH $(1,1)$ model

\begin{tabular}{|c|c|c|c|}
\hline \multicolumn{4}{|c|}{$\begin{array}{l}R_{t}=\alpha_{0}+\alpha_{1} D_{1}+\alpha_{2} D_{2}+\alpha_{3} R_{t-1}+\varepsilon_{t} \\
E\left(\varepsilon_{t}\right)=\mu_{0}-R_{t} \\
h_{t}=\tau_{0}+\tau_{1} D_{1}+\tau_{2} D_{2}+\beta_{1} h_{t-i}+\beta_{2} \varepsilon_{t-1}^{2}+\beta_{3} \bar{S}_{t-1} \varepsilon_{t-1}^{2} \\
\qquad 1 \text { if } \varepsilon_{t-1}<0 \\
\text { where } \overline{\mathrm{S}}_{t-1}=\left\{0 \text { if } \varepsilon_{t-1} \geq 0\right. \\
D_{1} \text { denotes the dummy of the change of ruling party and } D_{2} \text { denotes the } \\
\text { dummy of } 1987 \text { crash }\end{array}$} \\
\hline Variable & Return & & Volatility \\
\hline$\alpha_{0}$ & $99-4(4.83)^{\star \star \star}$ & $\tau_{0}$ & $29-6(7.28)^{\star \star \star}$ \\
\hline$\alpha_{1}$ & $-33^{-2}(-3.30)^{\star \star *}$ & $\tau_{1}$ & $51^{-4}(1.43)$ \\
\hline$\alpha_{2}$ & $-61-4(-2.48)^{* *}$ & $\tau_{2}$ & $55^{-6}(8.28)^{\star * \star}$ \\
\hline \multirow[t]{6}{*}{$\alpha_{3}$} & $0.20(42.67)^{\star \star *}$ & & \\
\hline & & Coefficient & Estimation \\
\hline & & $\beta_{1}$ & $0.76(106.43)^{\star \star \star}$ \\
\hline & & $\beta_{2}$ & $0.23(21.60)^{\star \star *}$ \\
\hline & & $\beta_{3}$ & $12^{-3}(1.03)$ \\
\hline & & Log-likelihood & 22045.86 \\
\hline
\end{tabular}

Notes: Numbers in parentheses are $t$-statistic. $* * *, * *$ and $*$ indicate statistical significance at the $1 \%, 5 \%$ and $10 \%$ significance levels, respectively. This table shows the impact of the change of ruling party, the 1987 stock market crash and the previous day's returns on next day's returns. The table also shows the impact of the above two mentioned dummy variables plus the previous day's volatility and negative noise on the next day's volatility. The two equations comprise a GJR-GARCH model which has two dummy variables which explain the impact of the change of ruling party and the 1987 stock market crash on volatility. $\alpha_{0}, \alpha_{1}, \alpha_{2}$, and $b_{1}$ are the coefficients for the constant, dummy for the change of ruling party, dummy for the 1987 stock market crash and the previous day's returns of stock, respectively. $\tau_{0}, \tau_{1}, \tau_{2}, \beta_{1}, \beta_{2}$ and $\beta_{3}$ are the coefficients for the constant, the dummy for the change of ruling party, the dummy for the 1987 stock market crash, the coefficient of the previous day's volatility, the coefficient of previous day's noise and the coefficient of the previous day's negative noise, respectively.

\section{Summary and conclusion}

This study examines the impact of the Greek political elections over the period from January 1985 to February 2008 on the ASE returns around the election dates by employing the standard event study methodology and ARCH-type models. The empirical results indicate a positive stock market reaction on the last working day prior to election date and negative on the first post-election day. In addition, the impact of elections on the ASE return is investigated and it is found that this is significantly affected by the transition of the ruling party from all the GARCH models while volatility affected only from the AR(1)-EGARCH model. The impact of the October 1987 stock markets crash on the ASE return (volatility) is found to be negative (positive) and statistically significant at the $5 \%$ significance level (statistically significant at the $5 \%$ significance level).

The results of this paper might have important implications for investors with an interest in the Greek stock market. In particular, they can affect decisions regarding the entry or exit of the ASE and the change of investment strategies. In spite of the elections' results, there is an abnormal positive reaction before the day of the elections which is followed by a negative abnormal return on the first post-election day and a reverse thereafter. This result raises doubts for the efficiency of the Greek stock market since it appears that the ASE needs some time to incorporate the election news. Furthermore, the rising volatility during the election dates and the associated negative returns reveal that investors bear election-induced risk, however, without being compensated with a premium. Additionally, the 1987 stock market crash is also found to have a significant impact on the ASE stock price returns and volatility. This result implies that the Greek stock market is vulnerable to global economic crises as much as the other developed capital markets.

\section{References}

1. Aggarwal, C., Inclan, C., and Leal, R. (1999). Volatility in emerging stock markets, Journal of Financial and Quantitative Analysis, 34, pp. 33-55.

2. Alexakis, P. and Xanthakis, M. (1995). Day of the week effect on the Greek stock market, Applied Financial Economics, 5, pp. 43-50.

3. Al-Khazali, O., Koumanakos, E. And Pyun, C.S. (2008). Calendar anomaly in the Greek stock market: Stochastic dominance analysis, International Review of Financial Analysis, 17, pp. 461-474. 
4. Atesoglou, S.H. and Congleton, R. (1982). Economic conditions and national elections post-sample forecasts of the Kramer equations, American Political Science Review, 76, pp. 873-875.

5. Bialkowsky, J., Gottschalk, K. and Wisniewski, T.P. (2008). Stock market volatility around national elections, Journal of Banking and Finance, forthcoming.

6. Bittlingmayer, G. (1998). Output, stock volatility, and political uncertainty in a natural experiment: Germany, Journal of Finance, 53, pp. 2243-2258.

7. Bollerslev, T. (1986). Generalized autoregressive conditional heteroskedasticity, Journal of Econometrics, 31, pp. 307-327.

8. Bratsiotis, G.J. (2000). Political parties and inflation in Greece: The metamorphosis of the socialist party on the way to EMU, Applied Economics Letters, 7, pp. 451-454.

9. Brown, S. and Warner, J. (1985). Using daily stock return: The case of event studies, Journal of Financial Economics, 14, pp. 3-32.

10. Burdekin, R. (1988). Economic performance and the determination of presidential elections in the US, American Economist, 32, pp. 71-75.

11. Chan, Y. and Wei, J. (1996). Political risk and stock price volatility: The case of Hong Kong, Pacific Basin Finance Journal, 28, pp. 247-253.

12. Coutts, A.J., Kaplanidis, C. and Roberts, J. (2000). Security price anomalies in an emerging market: The case of the Athens Stock Exchange, Applied Financial Economics, 10, pp. 561-571.

13. Dodd, P. and Warner, J. (1983). On corporate governance: a study of proxy contests, Journal of Financial Economics, 11, pp. 401-438.

14. Engle, R.F. (1982). Autoregressive conditional heteroskedasticity with estimates of the variance of United Kingdom inflation, Econometrica, 50, pp. 987-1007.

15. Engle, R.F. and Ng, V. (1993). Measuring and testing the impact of news on volatility, Journal of Finance, 45 , pp. 1749-1777.

16. European Commission (1993). On Investment Services in the Securities Field, Official Journal of the European Communities, No. L 211.

17. Foerster, S.R. and Schmitz, J.J. (1997). The transmission of US election cycles to international stock returns, Journal of International Business Studies, 28, pp. 1-27.

18. Gemmill, G. (1992). Political risk and market efficiency: Tested based on British stock and option markets in the 1987 election, Journal of Banking and Finance, 16, pp. 211-31.

19. Glosten, L.R., Jagannathan, R. and Runkle, D. (1993). On the relation between the expected value and the volatility of the nominal excess return on stocks, Journal of Finance, 48, pp. 1779-1801.

20. Huang, R.D. (1985). Common stock returns and presidential elections, Financial Analysts Journal, 41, pp. 58-61.

21. Kim, H.Y. and Mei, J.P. (2001). What makes the stock market jump? An analysis of political risk on Hong Kong stock returns, Journal of International Money and Finance, 20, pp. 1003-1016.

22. Lin, C.Y., and Wang, Y. (2005). An analysis of political changes on Nikkei 225 stock returns and volatilities, Annals of Economics and Finance, 6, pp. 169-183.

23. Mills, T.C., Siriopoulos, C., Markellos, R.N. and Harizanis, D. (2000). Seasonality in the Athens Stock Exchange, Applied Financial Economics, 10, pp. 137-142.

24. Nelson, D. (1991). Conditional heteroskedasticity in asset returns: A new approach, Econometrica, 59, pp. $347-370$.

25. Nieh, C. (2002). The effect of the Asian financial crisis on the relationships among macroeconomic factors for Asian countries, Applied Economics, 34, pp. 491-502.

26. Nordhaus, W.D. (1975). The Political Business Cycle, Review of Economic Studies, 43 (2), pp. 169-190.

27. Pantzalis, C., Stangeland, D.A. and Turtle, H.J. (2000). Political elections and the resolution of uncertainty: The international evidence, Journal of Banking and Finance, 24, pp. 1575-1604.

28. Peel, D. and Pope, P. (1983). General elections in the UK in the post 1950 period and the behavior of the stock market, Investment Analyst, 67, pp. 4-10.

29. Siokis, F. and Kapopoulos, P. (2007). Parties, elections and stock market volatility: Evidence from a small open economy, Economics and Politics, 19, pp. 123-285.

30. Tsangarakis, N. (2008), The day-of-the-week effect in the Athens Stock Exchange, Applied Financial Economics, 17, pp. 1447-1454. 